\title{
Migration of Mononuclear Cells Expressing $\beta$-Actin Through the Adventitia into Media and Intima in Coronary Arteriogenesis and Venogenesis in Ischemic Myocardium
}

\author{
Yasuto Uchida, ${ }^{1}$ MD, Yasumi Uchida, ${ }^{2,3}$ MD, Yoshiro Maezawa, ${ }^{4}$ MD, Yuko Maezawa, ${ }^{5}$ MD, \\ and Tsuyoshi TAвAтA, ${ }^{6} \mathrm{PhD}$
}

\begin{abstract}
SUMmaRY
It was previously thought that arteriogenesis and venogenesis are induced not only by proliferation of vessel-resident smooth muscle cells (SMCs) and endothelial cells (ECs) but also by migration of their precursors. However, it is not well understood through what route(s) the precursors migrate into the existing vessels.

We examined through what route or routes circulating mononuclear cells expressing $\beta$-actin $(\beta$-MNCs), which we identified in canine coronary vessels, migrate into coronary vessel walls and cause arteriogenesis and venogenesis at 1,2 , 4 and 8 weeks after induction of myocardial infarction.

The following changes were observed: (1) The $\beta$-MNCs migrated via coronary microvessels to the interstitial space at one week; (2) $\beta$-MNCs traversed the adventitia into the media and settled in parallel with pre-existing smooth muscle cells (SMCs) in arterioles and arteries and lost $\beta$-actin and acquired $\alpha$-smooth muscle actin ( $\alpha$-SMA) to become mature SMCs at 2-4 weeks; (3) at the same time, other $\beta$-MNCs migrated across the adventitia and media into the intima and settled in parallel with pre-existing endothelial cells (ECs) and lost $\beta$-actin, while acquiring $\mathrm{CD}_{31}$, to become mature ECs, resulting in arteriogenesis; (4) Similarly, $\beta$-MNCs migrated into venular and venous walls and became SMCs or ECs, resulting in venogenesis.

$\beta$-MNCs in the interstitial space expressed $\mathrm{CD}_{34}$ but not other major vascular cell markers.

$\beta$-MNCs, possibly a vascular progenitor, migrate not from the lumen but across the adventitia into the media or intima of coronary vessels and transit to SMCs or ECs, and participate in arteriogenesis and venogenesis in ischemic myocardium. (Int Heart J 2012; 53: 54-63)
\end{abstract}

Key words: Arteriogenesis, $\beta$-MNCs, Collateral development, Myocardial infarction, Venogenesis

$\mathrm{T}$ he term arteriogenesis refers to the growth of arterioles and arteries, ie, collateral development. Arteriogenesis is essential to the re-establishment of an adequate blood supply to ischemic organs and tissues. It was previously thought that compared to angiogenesis (capillary formation), arteriogenesis is a distinct process based on the remodeling and maturation of pre-existing arterioles and arteries, ${ }^{1)}$ characterized by proliferation of pre-existing smooth muscle cells (SMCs), endothelial cells (ECs), or their resident precursors. ${ }^{2}$

Recent reports that arteriogenesis is augmented by bone marrow mononuclear cells ${ }^{3-5)}$ and endothelial progenitor cells suggest involvement in arteriogenesis of not only proliferation of resident cells, but also migration and proliferation of circulating stem cells/precursor cells. ${ }^{6-8)}$ Although previous studies have demonstrated capillary formation (vasculogenesis/angiogenesis) by transplanted cells, ${ }^{7-10)}$ they could not demonstrate incorporation of transplanted cells into pre-existing arterioles and arteries, inducing arteriogenesis. In contrast to arteriogenesis, few studies have been conducted examining venogenesis, and little is known about its mechanisms.
In experimental studies of therapeutic angiogenesis and arteriogenesis, ${ }^{5,11-14)}$ we identified circulating mononuclear cells (MNCs) expressing $\beta$-actin, ie, $\beta$-MNCs, in canine coronary microvessels during myocardial ischemia. We therefore examined through what route(s) they migrate into the existing coronary vessels and participate in arteriogenesis and venogenesis.

\section{MeThods}

Myocardial infarction model: We conducted animal experiments at The Jikei University School of Medicine Institute for Animal Experiments. The experimental protocol was approved by the University Administrative Panel on Laboratory Animal Care.

For the experiment, 28 beagles were anesthetized with pentobarbital sodium (30 mg/kg i.v.). An $8 \mathrm{~F}$ catheter was introduced via the right common carotid artery into the left coronary ostium. After confirmation of the coronary anatomy by angiography, the left anterior descending artery was occluded

From the ${ }^{1}$ Department of Cardiology, Toho University Medical Center Ohmori Hospital, Tokyo, ${ }^{2}$ Japan Foundation for Cardiovascular Research, Chiba, ${ }^{3}$ Department of Cardiology, The Jikei University School of Medicine, Tokyo, Japan, ${ }^{4}$ Sick Children's Hospital, ${ }^{5}$ Samuel Lunenfeld Institute, Mount Sinai Hospital, Toronto, Canada, and ${ }^{6}$ Department of Clinical Physiology, Toho University Medical Center Sakura Hospital, Chiba, Japan.

Address for correspondence: Yasumi Uchida, MD, Japan Foundation for Cardiovascular Research, 2-30-17, Narashinodai, Funabashi, Chiba 274-0063, Japan.

Received for publication September 26, 2011.

Accepted October 20, 2011. 
by injecting a self-expandable polymer ball $(2 \times 2 \mathrm{~mm})$ into the artery. ${ }^{5,14)}$ After recovery from anesthesia, the animals were cared for according to the university guidelines.

After repeated coronary angiography and left ventriculography, the animals were sacrificed using intravenous pentobarbital sodium $(100 \mathrm{mg} / \mathrm{kg})$ and potassium chloride $(10 \mathrm{mg} /$ $\mathrm{kg}$ ) (7 animals each 1, 2, 4 and 8 weeks later). The heart was excised, and the border zones of the infarcted anterior wall of the left ventricle were excised and stored in $20 \%$ formaldehyde solution. In the other 6 control beagles in which myocardial infarction was not produced, the anterior wall was excised and stored similarly.

Angiographic assessment of coronary collateral development (arteriogenesis): Collateral development was classified angiographically as grade 0 (no contrast flow), grade 1 (small flow but incomplete opacification of the distal vessel), grade 2 (slow distal filling but full opacification of the distal vessel), and grade 3 (prompt antegrade flow and rapid clearing). ${ }^{15}$ )

Immunohistochemical staining: In a preliminary study, different to immunostaining of vascular cells in vitro and in mice or rats in vivo, double staining of $\beta$-actin and other cell markers in a given cell was difficult in canine coronary vessels. Therefore, adjacent slices were immunostained for cell markers using an- tibodies. By this procedure, a single cell could yield 2 slices and therefore 2 different cell markers could be stained in the same cell.

The excised border zone of the infarcted myocardium was cut into successive $2.5 \mu \mathrm{m}$ thick slices, and the slices were immunohistochemically stained for various cell markers. The cells in the interstitial space were stained for cell identity of $\beta$-SMCs because it was difficult to identify a given cell in the vessel wall using two slices: $\beta$-actin (monoclonal anti- $\beta$-actin clone AC-15, mouse ascites fluid, Sigma Co, St Louis, USA), which is considered to be a cytoplasmic actin and a marker of the synthetic phenotype of vascular smooth muscle cells (SMCs) in vitro, ${ }^{16)} \mathrm{CD}_{34}$ (Epitomics Inc., Burlingame, USA) for bone marrow mesenchymal cells, ${ }^{17)} \alpha$-smooth muscle actin ( $\alpha$-SMA; Sigma Co.) for contractile phenotype of vascular SMCs; vimentin (Dako Epos, Glostrup, Denmark) for SMCs, fibroblasts and myofibroblasts; ${ }^{18,19)}$ vimentin (Dako Epos) for VSMCs; ${ }^{18,19)}$ smooth muscle myosin heavy chain -1 (SM-1; Abcam Co, Cambridge, MA, USA), a specific marker for matured SMCs; ${ }^{20)} \mathrm{N}$-cadherin, a specific marker for myofibroblasts (Epitomics Inc.); ${ }^{21)}$ and $\mathrm{CD}_{31}$ (Abgent Co, San Diego, USA) for endothelial cell (ECs). ${ }^{17)}$

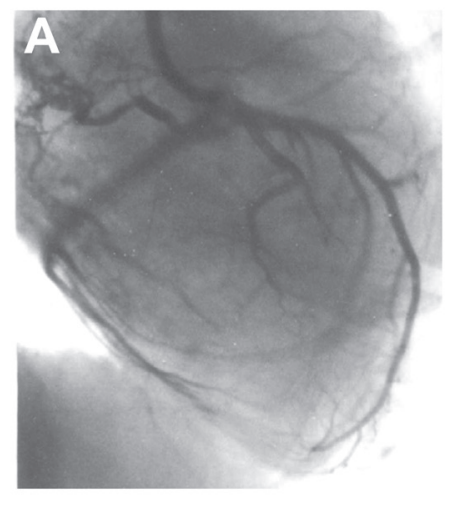

D

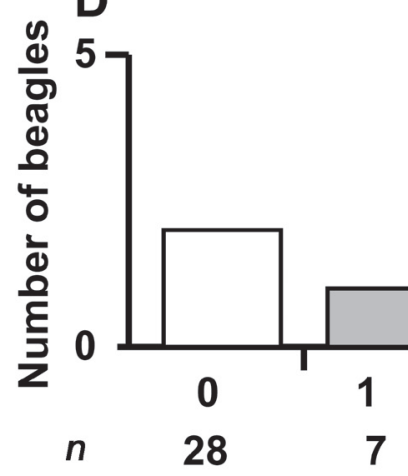

Figure 1. Angiographic visualization of canine coronary arteriogenesis (collateral development) following myocardial infarction. Acute myocardial infarction was induced in beagles by transcatheter occlusion of the middle segment of the left anterior descending coronary artery using a self-expandable polymer ball. A: before coronary occlusion. B: immediately after coronary occlusion (arrow). Total occlusion usually induced by swelling of the polymer around 10 minutes after polymer injection. C: Eight weeks after occlusion. Good (Rentrop grade 3) collaterals can be seen (arrow), indicating arteriogenesis. D: Angiographic grading of collateral development using Rentrop's grading immediately (0), $1,2,4$ and 8 weeks after coronary occlusion. $n$ : number of beagles examined. Angiographically visible collaterals increased from 4 weeks on. 


\section{$\beta$-actin}
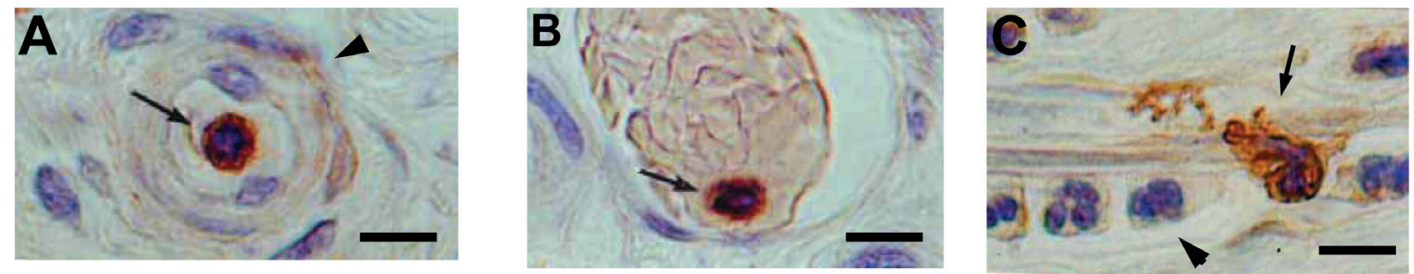

$\beta$-actin

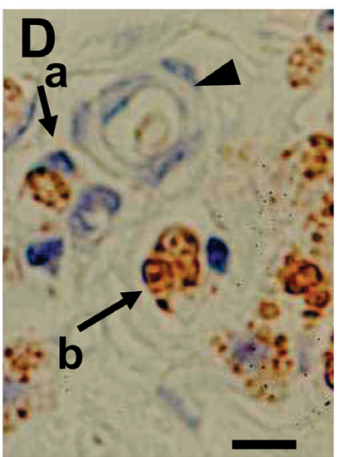

CD34

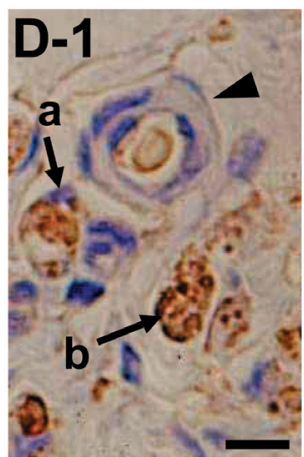

$\beta$-actin

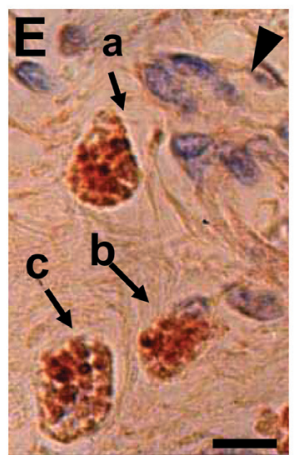

$\alpha$-SMA

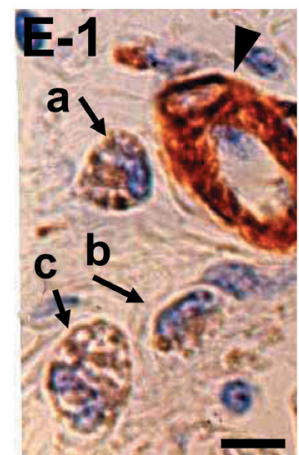

Figure 2. $\beta$-MNCs in the coronary lumen and interstitial space. A: A $\beta$-MNC (arrow) can be seen in an arteriolar lumen (arrowhead). B: A $\beta$-MNC in a venular lumen (arrow). C: A $\beta$-MNC (arrow) is just migrating across a capillary wall into the interstitial space. Arrowhead: $\beta$-actin-negative MNC. D, D-1: two adjacent successive slices showing that $\beta$-MNCs also contain $\mathrm{CD}_{34}$, suggesting that $\beta$-MNCs are of bone marrow origin. a in $\mathbf{D}$ and $\mathbf{D}$-1: the same cell. b in $\mathbf{D}$ and D-1: the same cell. Arrowheads in D and D-1: the same arteriole. a to $\mathrm{c}$ in $\mathbf{E}$ and a to c in E-1: the same cells. $\beta$-MNCs did not express $\alpha$-SMA. Horizontal bars in this and following figures: $10 \mu \mathrm{m}$.

Table I. Density of $\beta$-MNCs in the Interstitial Space

\begin{tabular}{l}
$\begin{array}{l}\text { Time from production } \\
\text { of myocardial infarction } \\
\text { (weeks) }\end{array}$ \\
\hline$n$
\end{tabular}

Classification of vessels by their structure and external diameter: Arterioles and arteries, and venules and veins, are structurally the same but have different diameters. Coronary vessels were defined according to the criteria described by Miwa, et $a l^{11)}$ as follows:

The external diameter of a vessel was defined as the thickness between the luminal surface and outer margin of the media.

1) Capillary: monolayered vessel constituted by ECs with an external diameter $<25 \mu \mathrm{m}$. 2) Arteriole: three layered vessel (intima, media, and adventitia) with an external diameter $\geq 25$ and $<100 \mu \mathrm{m}$. 3) Artery: three layered vessel with an external diameter $\geq 100 \mu \mathrm{m}$. 4) Venule: two layered vessel (intima and muscle layer) with an external diameter $\geq 25$ and $<100 \mu \mathrm{m}$. 5) Vein: two layered vessel with an external diameter $>100 \mu \mathrm{m}$.
Counting of arterioles, arteries, venules and veins: The number of $\beta$-MNCs/50 white blood cells, ie, $\beta$-MNC-density, in the coronary lumen, was counted, and comparisons made between controls and 1,2, 4 and 8 weeks after infarction. The number of $\beta$-MNCs $/ 250 \times 250 \mu \mathrm{m}^{2}$ of interstitial space of the border zone was also counted. For each beagle, 5 randomly selected border zones of the infarcted area were used for counting.

The numbers of arterioles/arteries and venules/veins containing $\beta$-actin-positive SMCs or $\beta$-MNCs in the media, and $\beta$-actin-positive ECs in the intima $/ 500 \times 500 \mu \mathrm{m}^{2}$ of border zone of the infarcted myocardium were counted.

Statistical analyses: Data are expressed as the mean \pm SD and were analyzed using Student's $t$ test. A $P<0.05$ was considered significant. 


\section{$\beta$-actin}
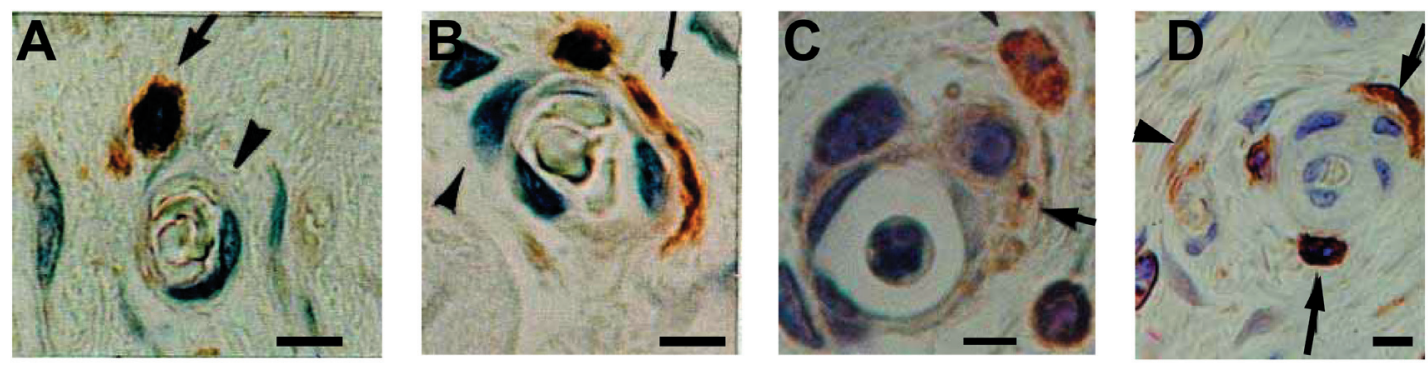

\section{$\beta$-actin}

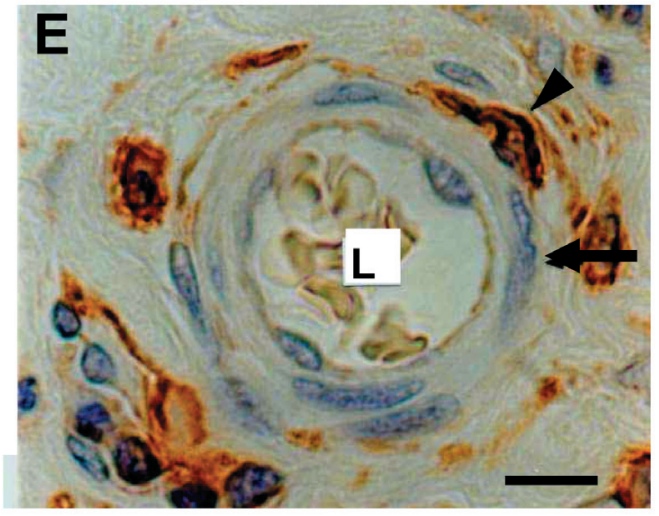

\section{$\alpha$-SMA}

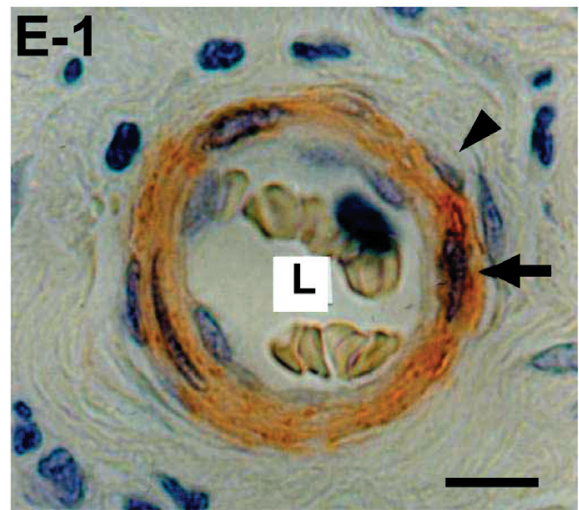

Figure 3. Process of $\beta$-MNC-induced coronary arteriogenesis. A-D: A $\beta$-MNC (arrow) in the interstitial space close to a capillary (arrowhead), a $\beta$-MNC (arrow) wrapping around an arteriole (arrowhead) with SMCs not expressing $\beta$-actin (arrowhead), a $\beta$-MNC (arrow) migrated into the media and almost lost $\beta$-actin, and $\beta$-MNCs (arrows) migrated into the media of an arteriole. A $\beta$-MNC (arrowhead in 2-2D), amoebic in configuration, migrating from a capillary into the interstitial space. E, E-1: 2 adjacent slices. A $\beta$-MNC, amoebic in configuration, just migrating into the media of an arteriole (arrowhead in $\mathbf{E}$ ). This $\beta$-MNC does not express $\alpha$-SMA (arrowhead in E-1). An SMC, amoebic in configuration, in the media (arrow in $\mathbf{E}$ ), not expressing $\beta$-actin, but expressing dense $\alpha$-SMA (arrow in E-1), indicating overproduction of $\alpha$-SMA, characteristic of a newly mature SMC.

\section{RESULTS}

Angiographically assessed collateral development (arteriogenesis): Figures $1 \mathrm{~A}$ to $1 \mathrm{C}$ show coronary angiograms performed before, immediately after, and 8 weeks after coronary occlusion, respectively. Rentrop grade 3 collaterals ${ }^{15)}$ were observed at 8 weeks, indicating arteriogenesis. The number of collaterals increased with elapsed time, and collaterals were observed in 4 of 7 beagles at 8 weeks (Figure 1D).

Circulating $\boldsymbol{\beta}$-MNCs in the coronary lumen: The $2.5 \mu \mathrm{m}$-thick slices obtained from the border zone of infarcted myocardium were stained for $\beta$-actin, which is considered to be a marker for the synthetic phenotype of vascular smooth muscle cells. ${ }^{16}$

$\beta$-MNCs were abundant in the lumen of coronary arterioles, capillaries, and venules after myocardial infarction (Figure 2).

Migration of $\boldsymbol{\beta}$-MNCs into the interstitial space: $\beta$-MNCs, amoebic in configuration, migrated frequently through the coronary vessel wall into the interstitial space at 1-2 weeks after myocardial infarction, more often through capillary walls and less often through arteriolar or venular walls (Figure 2C). $\beta$-MNCs were not uniformly distributed, but often clumped in
Table II. Cell Markers of $\beta$-Actin-Positive Mononuclear Cells ( $\beta$-MNCs) in the Interstitial Space

\begin{tabular}{ccccccc}
\hline $\begin{array}{c}\text { Number of } \\
\beta \text {-MNCs }\end{array}$ & $\alpha$-SMA & Vimentin & SM-1 & N-cadherin & $\mathrm{CD}_{31}$ & $\mathrm{CD}_{34}$ \\
\hline 7 & 0 & & & & & \\
5 & & 0 & & & & \\
6 & & & 0 & & & \\
7 & & & & 0 & 0 & \\
7 & & & & & & 7 \\
7 & & & & & & \\
\hline
\end{tabular}

Two adjacent slices in which the same cell contained were immunostained with different markers to examine whether a $\beta$-MNC expresses another marker. $\beta$-MNCs expressed $\mathrm{CD}_{34}$ but not other markers.

groups in the interstitial space. Their number was greatest at 1 week and decreased thereafter (Table I).

Characterization of $\boldsymbol{\beta}$-MNCs: Other cell markers of $\beta$-MNCs in the interstitial space were examined because identification of a given cell located in the interstitial space in 2 adjacent 

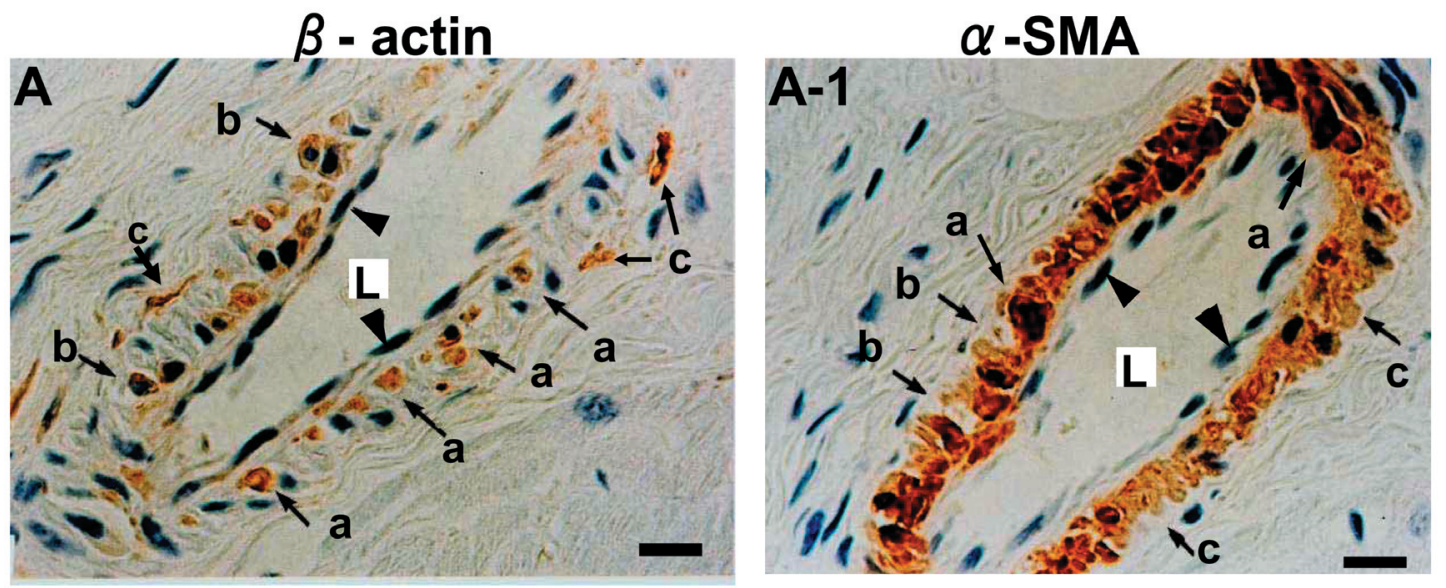

\section{$\beta$-actin}
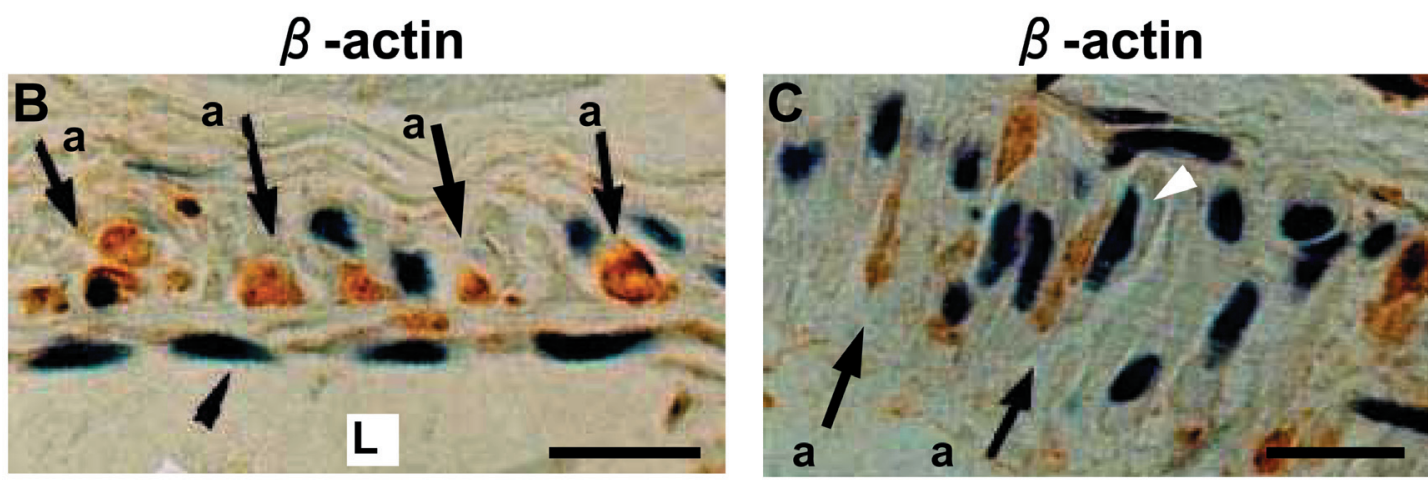

Figure 4. Migration of $\beta$-MNCs from the adventitia into the media to become SMCs. A, A-1: Two adjacent slices showing an arteriole at an oblique projection. A: $\beta$-actin stain. Multiple $\beta$-actin-positive SMCs (a) settled between $\beta$-actin-negative SMCs (possibly pre-existing mature SMCs), indicating that they transformed from $\beta$-MNCs. b: $\beta$-MNCs migrating into the media. c: A $\beta$-MNC in the adventitia. Arrowhead: EC. L: lumen. A-1: $\alpha$-SMA stain. SMCs expressing dense $\alpha$-SMA (a) and light $\alpha$-SMA (c) can be seen, indicating that the former are SMCs transformed from $\beta$-MNCs, and the latter are pre-existing SMCs. $\alpha$-SMA-absent portions (b) indicate where $\beta$-actin positive and $\alpha$-SMA negative SMCs, ie, immature SMC, that transformed from $\beta$-MNCs settled. L: lumen. B: $\beta$-actin-positive SMCs, ie, immature SMCs (arrows a) settled in the media beneath the ECs (arrowhead) C: $\beta$-actin positive SMCs, ie, immature SMCs (arrows a) settled in parallel with mature ( $\beta$-actin negative) circular SMCs (white arrowhead).

Table III. Coronary Vessels Having SMCs or ECs Expressing $\beta$-actin

\begin{tabular}{|c|c|c|c|c|c|}
\hline $\begin{array}{l}\text { Time from production of myocardial infarction } \\
\text { (weeks) }\end{array}$ & $\mathrm{C}$ & 1 & 2 & 4 & 8 \\
\hline$n$ & 6 & 7 & 7 & 7 & 7 \\
\hline \multicolumn{6}{|l|}{ A. Arterioles $/ 500 \times 500 \mu \mathrm{m}^{2}$ of myocardial area } \\
\hline 1) Total number & $12.0 \pm 2.9$ & $10.7 \pm 2.9$ & $14.7 \pm 4.1$ & $31.8 \pm 4.7^{* * * *}$ & $32.0 \pm 15.4^{* *}$ \\
\hline 2) With SMCs expressing $\beta$-actin & $0.1 \pm 0.2$ & $0.0 \pm 0.0$ & $3.1 \pm 2.0^{*}$ & $13.8 \pm 3.6^{* * *}$ & $2.8 \pm 1.7^{* *}$ \\
\hline 3) With ECs expressing $\beta$-actin & $0.2 \pm 0.4$ & $0.7 \pm 0.8$ & $2.7 \pm 2.1^{*}$ & $13.9 \pm 5.8^{* * * *}$ & $0.5 \pm 1.3^{* *}$ \\
\hline \multicolumn{6}{|l|}{ B. Arteries $/ 1000 \times 1000 \mu \mathrm{m}^{2}$ of myocardial area } \\
\hline 1) Total number & $2.0 \pm 0.9$ & $2.4 \pm 1.0$ & $2.6 \pm 1.3$ & $4.6 \pm 2.6$ & $5.3 \pm 1.6^{* *}$ \\
\hline 2) With SMCs expressing $\beta$-actin & $0.0 \pm 0.0$ & $0.0 \pm 0.0$ & $0.1 \pm 0.4$ & $2.1 \pm 2.0$ & $0.5 \pm 0.8$ \\
\hline 3) With ECs expressing $\beta$-actin & $0.0 \pm 0.0$ & $0.4 \pm 0.5$ & $1.1 \pm 1.2^{*}$ & $1.7 \pm 1.4^{*}$ & $4.1 \pm 1.1^{* * * * *}$ \\
\hline \multicolumn{6}{|l|}{ C. Venules $/ 500 \times 500 \mu \mathrm{m}^{2}$ of myocardial area } \\
\hline 1) Total number & $7.3 \pm 2.3$ & $8.1 \pm 2.3$ & $12.2 \pm 2.7^{*}$ & $16.5 \pm 4.2^{*}$ & $16.5 \pm 3.2^{* *}$ \\
\hline 2) With SMCs expressing $\beta$-actin & $0.3 \pm 0.5$ & $0.4 \pm 0.5$ & $2.1 \pm 2.1^{*}$ & $7.6 \pm 3.2^{* *}$ & $1.7 \pm 1.4$ \\
\hline 3) With ECs expressing $\beta$-actin & $0.3 \pm 0.5$ & $1.3 \pm 0.8$ & $2.4 \pm 1.7^{*}$ & $8.4 \pm 2.9^{* *}$ & $1.7 \pm 11.3^{*}$ \\
\hline \multicolumn{6}{|l|}{ D. Veins $/ 1000 \times 1000 \mu \mathrm{m}^{2}$ of myocardial area } \\
\hline 1) Total number & $2.3 \pm 1.0$ & $2.7 \pm 1.8$ & $2.9 \pm 1.2$ & $7.8 \pm 2.4^{*}$ & $7.9 \pm 3.2^{*}$ \\
\hline 2) With SMCs expressing $\beta$-actin & $0.0 \pm 0.0$ & $0.0 \pm 0.0$ & $0.3 \pm 0.4$ & $1.0 \pm 0.8$ & $1.0 \pm 0.8^{*}$ \\
\hline 3) With ECs expressing $\beta$-actin & $0.0 \pm 0.0$ & $0.4 \pm 0.5$ & $1.0 \pm 0.6^{*}$ & $1.8 \pm 1.5^{*}$ & $7.7 \pm 2.4^{* * *}$ \\
\hline
\end{tabular}

$n$ : number of beagles. $C$ : beagles without myocardial infarction. ${ }^{*} P<0.05,{ }^{* *} P<0.01,{ }^{* * *} P<0.001,{ }^{* * * * *} P<0.0001$ versus Control. 


\section{$\beta$-actin}
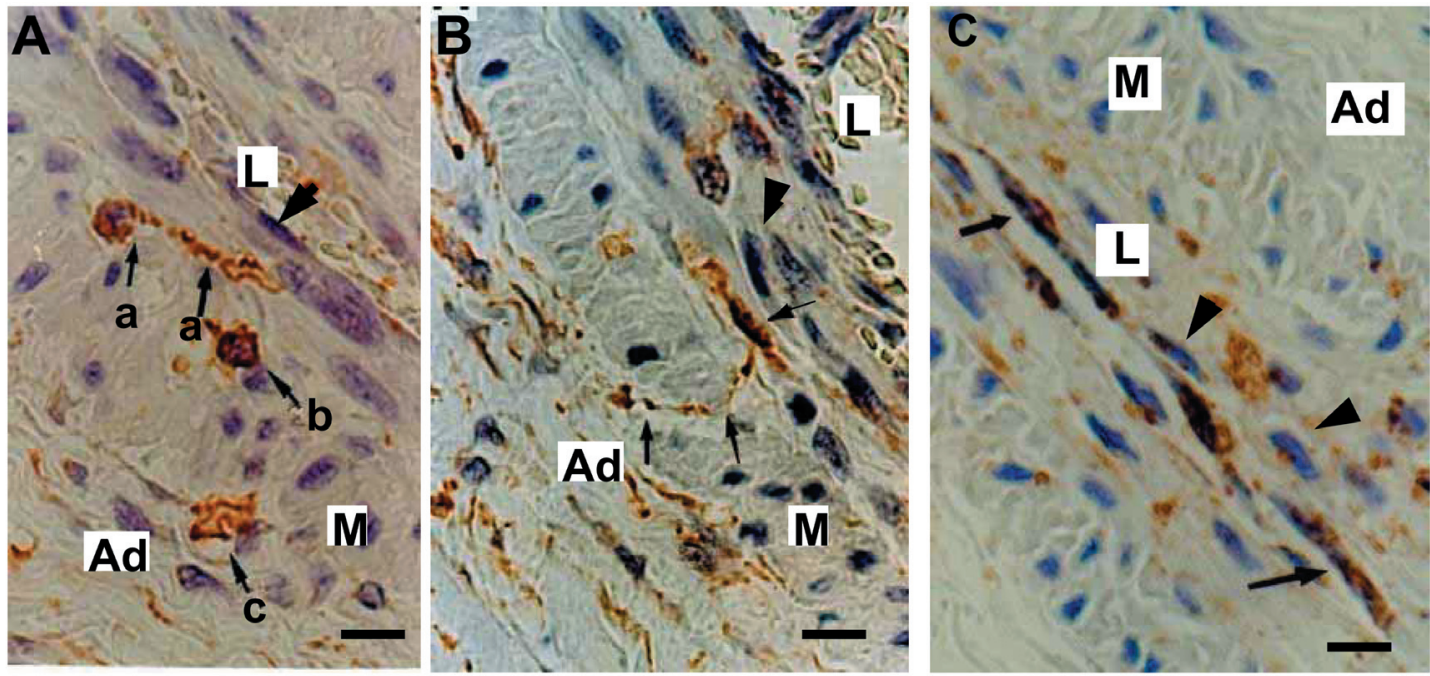

Figure 5. Migration of $\beta$-MNCs from the adventitia into the intima to become ECs. A: Migration of $\beta$-MNCs into the media and intima. a: A $\beta$-MNC migrating into the intima like an amoeba. b: A $\beta$-MNC in the media. c: A $\beta$-MNC in the adventitia. Arrowhead: EC. B: A $\beta$-MNC, amoebic in configuration, settling its head in the intima while leaving its tail in the adventitia (arrows). Arrowhead: EC. C: ECs expressing $\beta$-actin (arrows) settled in parallel with mature (not expressing $\beta$-actin) ECs (arrowheads). Ad: adventitia, M: media, L: lumen.

\section{$\beta$-actin}

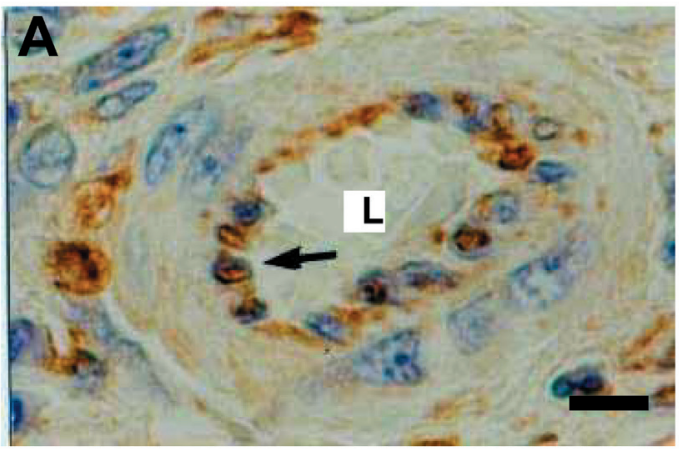

$\beta$-actin

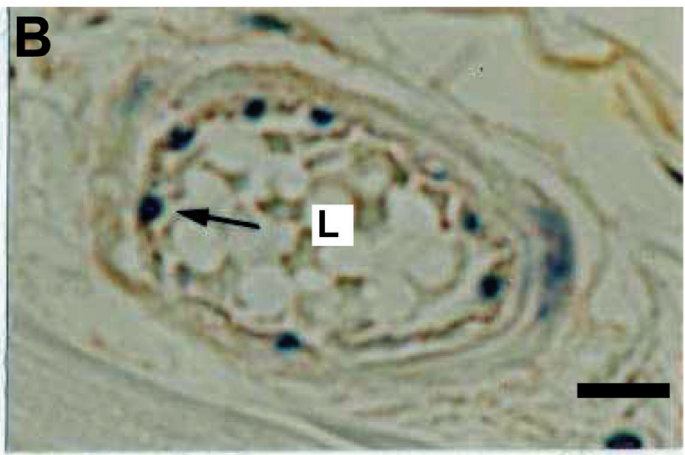

CD31

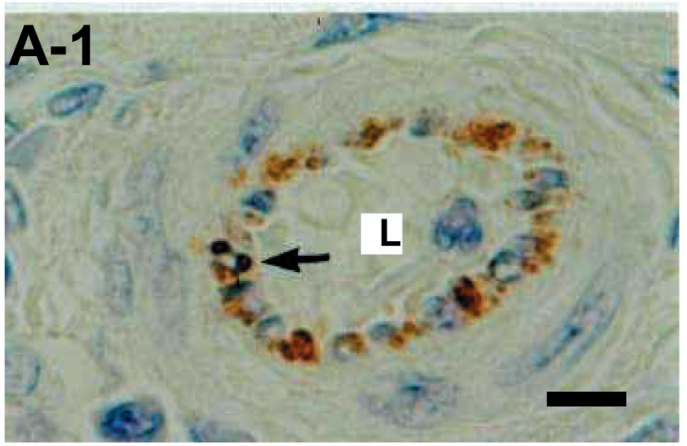

CD31

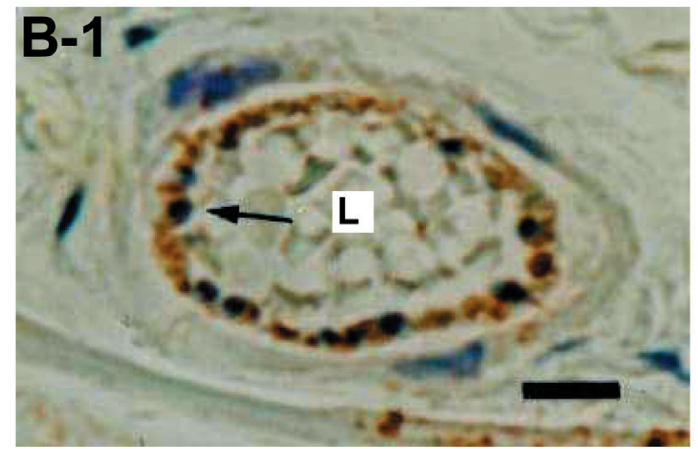

Figure 6. $\beta$-MNCs in the intima of arterioles. A, A-1: Two adjacent slices obtained 4 weeks after myocardial infarction. ECs expressed both $\beta$-actin and $\mathrm{CD}_{31}$ (arrows), indicating they are immature ECs. B and B-1: 2 adjacent slices obtained 8 weeks later. These ECs do not express $\beta$-actin, but express CD indicating they are mature ECs (arrows). 


\section{$\beta$-SMA}
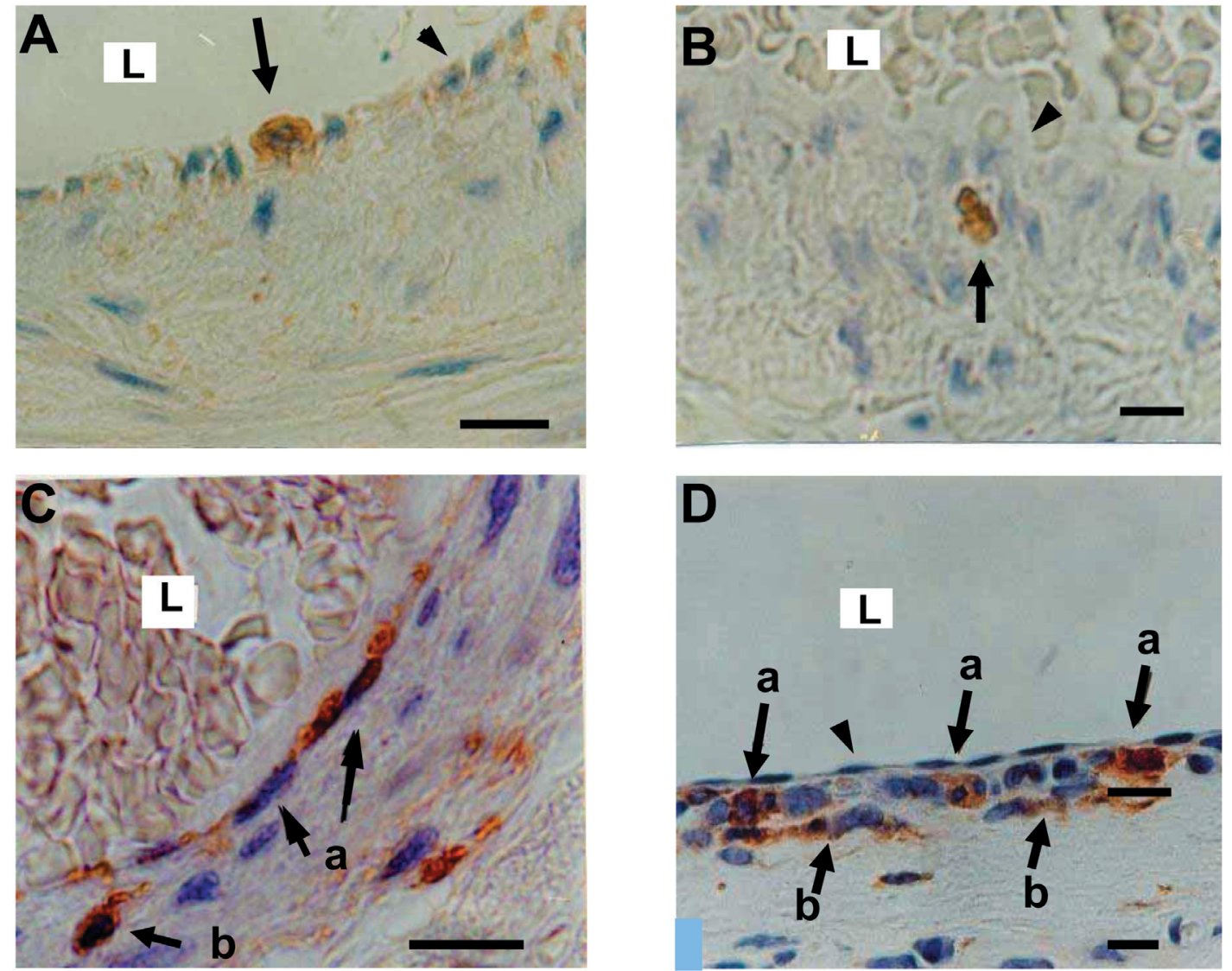

Figure 7. $\beta$-MNCs in arterial and venous walls. A: An EC expressing $\beta$-actin (arrow) in an artery (outer diameter $230 \mu \mathrm{m}$ ), indicating an immature EC. B: A $\beta$-MNC in the media of an artery (outer diameter $305 \mu \mathrm{m}$ ). Arrowheads in A and B: ECs not expressing $\beta$-actin, indicating mature ECs. C: ECs expressing $\beta$-actin (arrows a) in a vein (outer diameter $310 \mu \mathrm{m}$ ), indicating immature ECs. b: A $\beta$-MNC not transformed to either an SMC or EC. D: $\beta$-MNCs (arrows a) settled in the venous media beneath the endothelial cells (arrowhead) of a vein (outer diameter $360 \mu \mathrm{m}$ ), indicating that they are immature SMCs. Arrows b: migrated but not transformed to either an SMC or EC. All specimens were obtained 4 weeks after myocardial infarction.

slices was easier than those located in the adventitia or media. $\beta$-MNCs expressed $\mathrm{CD}_{34}$, a marker for bone marrow mesenchymal cells $^{17)}$ (Figure 2D to 2D-1), but not $\mathrm{CD}_{31}$, a marker for $\mathrm{ECs},{ }^{17)}$ vimentin, a marker for SMCs and fibroblasts/myofibroblasts, ${ }^{18,19)} \alpha$-SMA, a marker for the contractile phenotype of SMCs and fibroblasts/myofibroblasts, ${ }^{18,19)}$ SM-1, a specific marker for matured $\mathrm{SMC},{ }^{20)}$ nor N-cadherin, a specific marker for myofibroblasts (Table II). ${ }^{21)}$

Migration of $\beta$-MNCs through the adventitia into the media to become SMCs: At 1-2 weeks, $\beta$-MNCs attached to or wrapped around pre-existing small arterioles (Figures 3B, 3C). In larger arterioles or arteries, $\beta$-MNCs with an amoebic configuration migrated through the adventitia into the media (Figure 3D). During this migration, they changed to a spindle-like shape, lost $\beta$-actin, and acquired $\alpha$-SMA (Figures 3C, 3E, 3E-1). The acquired $\alpha$-SMA was denser than that of pre-existing SMCs (arrow in Figure 3E-1), indicating overproduction of $\alpha$-SMA, enabling discrimination of newly formed SMCs from pre-existing SMCs. $\beta$-MNCs migrating from nearby capillaries to ar- terioles or arteries were frequently observed (Figure 3D).

At 2-4 weeks, in addition to $\beta$-MNCs that were amoebic in configuration, spindle-shaped SMCs expressing $\beta$-actin (immature SMCs) were observed in the media. They settled themselves between $\beta$-actin-negative SMCs (possibly pre-existing mature SMCs) (Figures 4A, 4B, 4C). The number of arterioles and arteries with SMCs expressing $\beta$-actin or $\beta$-MNCs in the media was greatest at 2-4 weeks, and had declined by 8 weeks (Table III).

Migration of $\beta$-MNCs through the adventitia and media into the intima to become ECs: At 2-4 weeks after myocardial infarction, $\beta$-MNCs amoebic in configuration traversing the adventitia and media into the intima were frequently observed in arterioles and arteries (Figure 5A). After migration into the intima, without losing $\beta$-actin they settled between $\beta$-actinnegative ECs (mature and possibly pre-existing ECs), indicating they were immature ECs (Figures 5B, 5C).

Arterioles and arteries with ECs expressing both $\beta$-actin and CD31 (a marker of ECs) were most frequently observed at 


\section{$\beta$-actin}

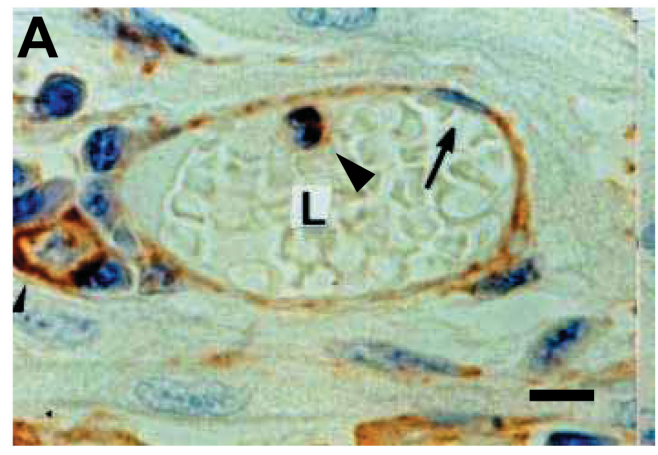

\section{$\beta$-actin}

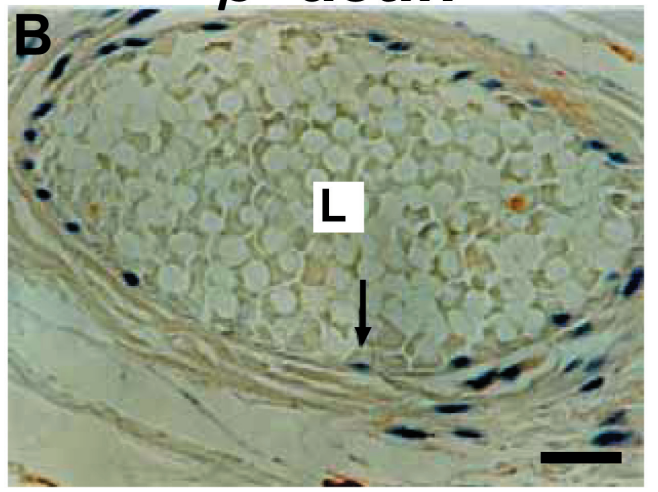

CD31

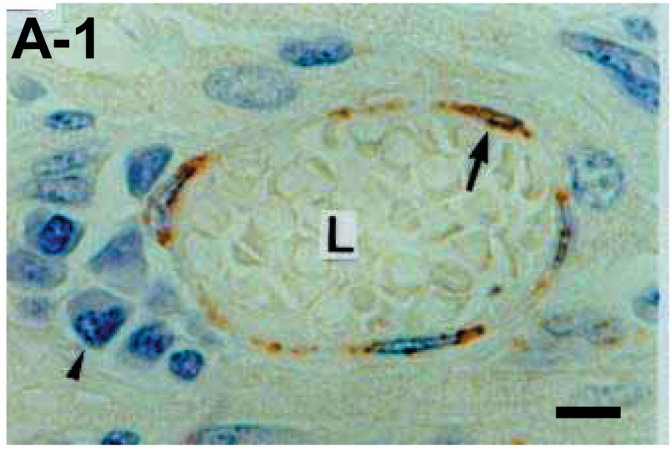

CD31

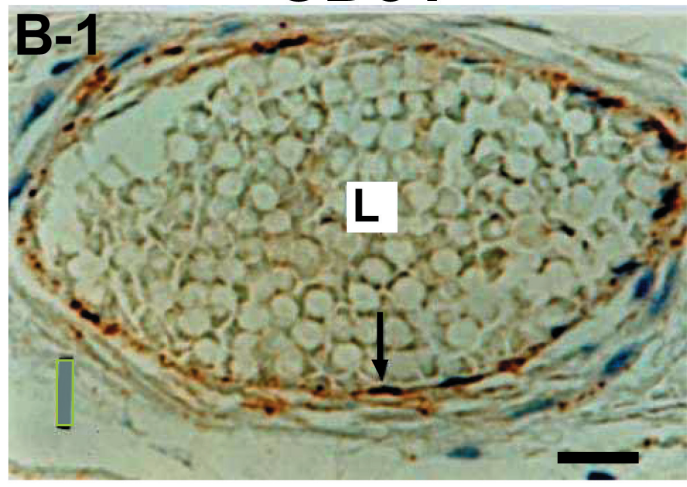

Figure 8. $\beta$-MNCs in venules. A, A-1: Two adjacent slices obtained 4 weeks after myocardial infarction. ECs expressing both $\beta$-actin (arrow in A) and $\mathrm{CD}_{31}$ (arrow in A-1), indicating they are immature ECs. B, B-1: 2 adjacent slices obtained 8 weeks after myocardial infarction. ECs not expressing $\beta$-actin (arrow in $\mathrm{B}$ ), but expressing $\mathrm{CD}_{31}$ (arrow in B-1), indicating they are mature ECs.

4 weeks, and had declined by 8 weeks (Figures 6A, 6A-1, Table III).

Conversely, arterioles and arteries with SMCs not expressing $\beta$-actin, and ECs expressing CD31 but not $\beta$-actin, were most frequently observed at 8 weeks, suggesting maturation of arterial collaterals (arteriogenesis) takes around 8 weeks (Figures 6B, 6B-1, Table III).

Migration of $\boldsymbol{\beta}$-MNCs through the venous adventitia into the media to become SMCs: As with arterioles and arteries, migration of $\beta$-MNCs through the adventitia into the venular and venous media or intima was frequently observed at 2-4 weeks. $\beta$-MNCs migrated slightly more densely to veins, like in venules, compared to arteries (Figures 7A, 7B). They settled between $\beta$-actin-negative ECs or SMCs (Figures 7C, 7D). Venules and veins with ECs expressing $\beta$-actin and $\mathrm{CD}_{31}$ were most frequently observed at 4 weeks (Figures 8A, 8A-1, Table IV). Venules and veins with ECs expressing $\mathrm{CD}_{31}$ alone were most frequently observed at 8 weeks, suggesting maturation of venous collaterals (venogenesis) takes around 8 weeks (Figures 8B, 8B-1, Table III).

\section{Discussion}

It was previously thought that arteriogenesis (collateral development) occurs in 3 stages: 1) Arterial occlusion or stenosis causes a steep pressure gradient along the shortest path within the interconnecting networks, increasing blood flow velocity and hence shear stress. This increase in shear stress activates ECs to secrete cytokines, attracting circulating monocytes/macrophages. 2) Monocytes migrate into the vascular wall and secrete cytokines and growth factors, inducing resident SMCs, ECs, and precursors highly mitogenic to proliferate, leading to growth of pre-existing vessels. 3) Extracellular matrix deposits induce mature collaterals. ${ }^{22-28)}$

A number of experimental and clinical arteriogenic therapies have been attempted using topical transplantation of growth factors or stem cells/precursors, with favorable results. ${ }^{5,11,12)}$ Although studies have demonstrated capillary formation (vasculogenesis/angiogenesis) by transplanted cells, ${ }^{11,12)}$ they could not confirm that transplanted cells migrating into pre-existing vessel walls became SMCs or ECs or their incorporation into vessels to enlarge them. Transplanted bone marrow-derived stromal cells and endothelial progenitor cells are considered to augment arteriogenesis through the release of 
cytokines rather than via cellular incorporation into the vessels. ${ }^{9,10)}$

Arteriogenesis by $\boldsymbol{\beta}$-MNCs: Although the present study was conducted as a point-to-point observation on migration of $\beta$-MNCs because of difficulties associated with serial observation of a given $\beta$-MNC in vivo, it is conceivable that contrary to our previous understanding of the processes of arteriogenesis, $\beta$-MNCs are recruited to the ischemic myocardium, migrating from pre-existing microvessels into the interstitial space, then migrating through the adventitia into the media and settling between mature SMCs. They then become mature SMCs by losing $\beta$-actin and acquiring $\alpha$-SMA, and also migrate into the intima and settle between mature ECs, and become mature ECs by losing $\beta$-actin while acquiring $\mathrm{CD}_{31}$. In this way, $\beta$-MNCs participate at least partly in arteriolar and arterial growth, ie, arteriogenesis. Although some participation by the proliferation of resident cells or other migrated cells cannot be denied, our findings strongly suggest that $\beta$-MNCs play a role in coronary arteriogenesis by migrating from outside of adventitia into the vessels in the ischemic myocardium.

Mature arterioles and arteries (SMCs and ECs not expressing $\beta$-actin) were increased at 8 weeks after myocardial infarction. Also, good collaterals were confirmed angiographically at 8 weeks. This agreement indicates that around 8 weeks are required for good collateral development (effective arteriogenesis).

Venogenesis by $\boldsymbol{\beta}$-MNCs: To date, little attention has been paid to the growth of venules and veins, ie, venogenesis, and it was simply considered that proliferation of resident cells induces venogenesis, as in the case of arteriogenesis.

In the present study, as with arteriogenesis, $\beta$-MNCs migrated through the adventitia into the media or intima of preexisting venules and veins, changing to mature SMCs and ECs, thus inducing venular and venous growth, ie, venogenesis. These findings are also quite different to the previous understanding that proliferation of resident cells induces venogenesis. ${ }^{3,4)}$

In the present study, $\beta$-MNCs migrated into the coronary vessel wall, not from the lumen but from outside, ie, the interstitial space, and contributed to arteriogenesis and venogenesis. This finding is also different to the previous understanding that circulating stem cells/precursor cells migrate into the vessel wall from the lumen and contribute to angiogenesis. ${ }^{\text {) }}$

After migrating into the vessel wall, $\beta$-MNCs became immature SMCs, and settled in parallel with pre-existing circular SMCs in the media, or in parallel with longitudinally arranged existing ECs in arterioles, arteries, venules, and veins. It remains to be clarified what factor(s) induce some $\beta$-MNCs to settle in the media, and others in the intima. It is possible that there are subtypes of $\beta$-MNCs that are predetermined to become SMCs or ECs. It also remains to be clarified what factor(s) guided them to settle in parallel with the pre-existing SMCs or ECs.

Characters of $\boldsymbol{\beta}$-MNCs: Based on immunohistological studies in cultured cells in vitro and in mice or mouse in vivo, it has been believed that $\beta$-actin is a cytoplasmic nonmuscle actin and prevalent in many cell lineages. Studies on $\beta$-actin in canine coronary vessels in vivo however have never been performed. In the present studies, it was revealed that $\beta$-actin is expressed in a certain type of circulating mononuclear cells in the canine coronary vessels, ie, $\beta$-MNCs. Therefore, we used this actin as a marker of the cells that participate in coronary arteriogenesis and venogenesis.

$\beta$-MNCs express $\mathrm{CD}_{34}$, a nonspecific marker for bone marrow origin, ${ }^{17}$ but not $\mathrm{CD}_{31}$, a marker for $\mathrm{ECs},{ }^{17,29)}$ vimentin, a marker for SMCs and myofibloblasts, ${ }^{30)} \alpha$-SMA, a marker for contractile phenotype of SMCs and fibroblasts/myofibroblasts, ${ }^{19-21)}$ SM-1, a marker for matured SMCs, ${ }^{20)}$ or N-cadherin, a marker for fibroblasts and myofibrolasts. ${ }^{21)} \beta$-MNCs are different from SMC progenitor cells or fibroblasts which do not express $\beta$-actin and $\mathrm{CD}_{31}{ }^{31}$.

It was reported that resident stem cells/progenitor cells are present in adventitia and can differentiate into SMCs and ECs. ${ }^{32)}$ Also, it was reported that resident fibroblasts/myofibroblasts which express $\alpha$-SMA are present in the adventitia and participate in intimal hyperplasia. ${ }^{18)}$ In the present study, however, $\alpha$-SMA-positive cells were not present and $\beta$-MNCs were sparse in the adventitia of intact coronary vessels. Further, $\beta$-MNCs migrating from outside of the adventitia into the media were frequently observed after induction of infarction. Furthermore, our present studies confirmed that $\beta$-MNCs transform to SMCs or ECs. All these findings indicate that $\beta$-MNCs are a vascular progenitor, at least of SMCs and ECs.

The SMCs and ECs differentiate from angioblasts in the embryo and from endothelial progenitor cells, mesoangioblasts, multipotent adult precursor cells, or side-population cells in adult bone marrow. ${ }^{1-4,33)}$ Although it is evident that $\beta$-MNCs are a multipotent vascular precursor, it remains unclear to what cell line $\beta$-MNCs belong.

Study limitations: The following questions remain to be answered: 1) To what cell lineage do $\beta$-MNCs belong? 2) What factor(s) induce migration of the $\beta$-MNCs through the adventitia into the media or intima, and triggers their transformation? 3) What factor(s) determine the settling position (media or intima) of new SMCs and ECs that transformed from $\beta$-MNCs?

\section{REFERENCES}

1. Katsanos K, Karnabatidis D, Diamantopoulos A, et al. Thrombin promotes arteriogenesis and hemodynamic recovery in a rabbit hindlimb ischemia model. J Vasc Surg 2009; 49: 1000-12.

2. Bearzi C, Leri A, Lo Monaco F, et al. Identification of a coronary vascular progenitor cell in the human heart. Proc Natl Acad Sci USA 2009; 106: 15885-90.

3. Khmelewski E, Becker A, Meinertz T, Ito WD. Tissue resident cells play a dominant role in arteriogenesis and concomitant macrophage accumulation. Circ Res 2004; 95: E56-64.

4. Schaper W. Collateral circulation: past and present. Basic Res Cardiol 2009; 104: 5-21. (Review)

5. Koga A. Selective arteriogenesis induced by transplantation of bone marrow mononuclear cells with all-trans retinoic acid to ischemic myocardium. Tokyo Jikeikai Med J 2004; 119: 413-9.

6. Sata M, Saiura A, Kunisato A, et al. Hematopoietic stem cells differentiate into vascular cells that participate in the pathogenesis of atherosclerosis. Nat Med 2002; 8: 403-9.

7. Grenier G, Scimè A, Le Grand F, et al. Resident endothelial precursors in muscle, adipose, and dermis contribute to postnatal vasculogenesis. Stem Cells 2007; 25: 3101-10.

8. Kawamoto A, Gwon HC, Iwaguro H, et al. Therapeutic potential of ex vivo expanded endothelial progenitor cells for myocardial ischemia. Circulation 2001; 103: 634-7.

9. Kinnaird T, Stabile E, Burnett MS, et al. Marrow-derived stromal cells express genes encoding a broad spectrum of arteriogenic cytokines and promote in vitro and in vivo arteriogenesis through 
paracrine mechanisms. Circ Res 2004; 94: 678-85.

10. Matsuo Y, Imanishi T, Hayashi Y, et al. The effect of endothelial progenitor cells on the development of collateral formation in patients with coronary artery disease. Intern Med 2008; 47: 127-34.

11. Yanagisawa-Miwa A, Uchida Y, Nakamura F, et al. Salvage of insfarcted myocardium by angiogenic action of basic fibroblast growth factor. Science 1992; 257: 1401-3.

12. Miwa A, Uchida $\mathrm{Y}$, Itoh $\mathrm{H}$. Role of FGF in myocardial infarction. Molecular Medicine 1993; 30: 1038-46.

13. Uchida Y, Nakamura F, Tomaru T, Yanagisawa A. Treatment of patients with arteriosclerosis obliterans by human recombinant basic FGF. In: Angiogenic therapy of ischemic heart disease. Uchida Y (ed), Japanese Circ Soc, Kyoto; 1997: 99-101.

14. Uchida Y, Yanagisawa-Miwa A, Nakamura F, et al. Angiogenic therapy of acute myocardial infarction by intrapericardial injection of basic fibroblast growth factor and heparin sulfate: an experimental study. Am Heart J 1995; 130: 1182-8.

15. Alderman E, Stadius M. The angiographic definition of the Bypass Angioplasty Revascularization Investigation. Coron Artery Dis 1992; 3: 1189-208.

16. Galustian C, Dye J, Leach L, Clark P, Firth JA. Actin cytoskeletal isoforms in human endothelial cells in vitro: alteration with cell passage. In Vitro Cell Dev Biol Anim 1995; 31: 796-802.

17. Guo S, Cheng Y, Ma Y, Yang X. Endothelial progenitor cells derived from CD34+ cells from cooperative vascular networks. Cell Physiol Biochim 2010; 26: 679-88.

18. Guo W, San B, Klingsberg RC, Qin X, Lashy JA. Abrogation of TGF-beta 1-induced fibroblast-myofibroblast differentiation by histone deacetylase inhibition. Am J Physiol Lung Cell Mol Physiol 2009; 297: L864-70.

19. Kohnen G, Campbell S, Jeffers MD, Cameron IT. Spatially regulated differentiation of endometrial vascular smooth muscle cells. Hum Reprod 2005; 15: 284-92.

20. Frid MG, Printesva OY, Chiavegato A, et al. Myosin heavy-chain isoform composition and distribution in developing and adult human aortic smooth muscle. J Vasc Res 1993; 30: 279-92.

21. Ji S, Wang X, Shu J, et al. In vitro generation of myofibloblastslike cells from liver epithelial progenitor cells of rhesus monkey
(Macaca mulatta). In Vitro Cell Dev Biol Anim 2011; 47: 383-90.

22. Schaper W, Buschmann I. Collateral circulation and diabetes. Circulation 1999; 99: 2224-6.

23. Kern MJ. Coronary blood flow and myocardial ischemia. In: Heart Disease 7th Edition, Zipes DP, Libby P, Bonow RO, Braunwald E (eds), Elsevier-Saunders, Philadelphia; 2005: 1103-27.

24. Schaper W, Ito WD. Molecular mechanisms of coronary collateral vessel growth. Circ Res 1996; 79: 911-9. (Review)

25. Pepper MS. Manipulating angiogenesis. From basic science to the bedside. Arterioscler Thromb Vasc Biol 1997; 17: 605-19. (Review)

26. Wolf C, Cai WJ, Vosschulte R, et al. Vascular remodeling and altered protein expression during growth of coronary collateral arteries. J Mol Cell Cardiol 1998; 30: 2291-305.

27. Stetler-Stevenson WG. Matrix metalloproteinases in angiogenesis: a moving target for therapeutic intervention. J Clin Invest 1999; 103: 1237-41. (Review)

28. Buschmann I, Heil M, Jost M, Schaper W. Influence of inflammatory cytokines on arteriogenesis. Microcirculation 2003; 10: 3719. (Review)

29. Gospodarowicz D, Moran J, Braun D, Birdwell C. Clonal growth of bovine vascular endothelial cells: fibroblast growth factor as a survival agent. Proc Natl Acad Sci USA 1976; 73: 4120-4.

30. Sato Y, Rifkin DB. Autocrine activities of basic fibroblast growth factor: regulation of endothelial cell movement, plasminogen activator synthesis, and DNA synthesis. J Cell Biol 1988; 107: 1199205.

31. Alt E, Yan Y, Gehmert S, et al. Fibroblasts share mesenchymal phenotypes with stem cells, but lack their differentiation and colony-forming potential. Boil Cell 2011; 103: 197-208.

32. Hu Y, Xu Q. Adventitial biology: differentiation and function. Arterioscler Thromb Vasc Biol 2011; 31: 1523-9. (Review)

33. Nickerson MM, Burke CW, Meisner JK, Shuptrine CW, Song J, Price RJ. Capillary arterialization requires the bone-marrow-derived cell (BMC)-specific expression of chemokine (C-C motif) receptor-2, but BMCs do not transdifferentiate into microvascular smooth muscle. Angiogenesis 2009; 12: 355-63. 